\title{
An unusual case report: normocalcemic markers and their relationship with multiple sclerosis in primary hyperparathyroidism disease revealed by radiological markers with the diagnosis of brown tumor
}

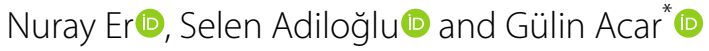

\begin{abstract}
Background: Brown tumor is a giant cell focal bone lesion associated with hyperparathyroidism and is more common in long bones such as the femur, ribs, pelvis, and clavicle, rather than in the head and neck region. Brown tumors occur less frequently in patients with primary hyperparathyroidism and are not usually a diagnostic marker of the disease. In addition, when primary hyperparathyroidism shows normocalcemic values and this disease is accompanied by multiple sclerosis, diagnosis becomes difficult.

Case presentation: A 57-year-old female patient presented with a painless, firm, irregularly circumscribed lesion extending from the upper palate to the nasal cavity. The lesion was first noticed by the patient about 2 months ago because it started to form asymmetry. The patient, whose anamnesis was learned to have Multiple Sclerosis (MS) and Chronic Obstructive Pulmonary Disease (COPD), was immobile. The patient was using medication only for COPD. After radiological and clinical examinations, the image in the maxilla was thought to be Brown Tumor and blood values were examined. After the incisional biopsy was also performed, it was evaluated together with the blood results and the diagnosis of brown tumor due to normocalcemic primary hyperparathyroidism was made. As in this case, brown tumor cases in which the calcium level remains within normal ranges, that is, due to Normocalcemic Hyperparathyroidism, are extremely rare, and 7 cases have been reported in the literature.

Conclusions: In the presented case, the importance of the radiological and clinical markers of the brown tumor developing due to normocalcemic hyperparathyroidism in the diagnosis is stated, the relationship of MS and the effects of the drugs used for MS at brown tumor formation is examined, and the importance of the treatment followup with radiological findings is stated. The features of the much rarer subgroups of relatively common diseases should be well known, and it should not be forgotten that the less frequently observed features can sometimes be the first indicator. And when large-limited lesions are identified, additional systemic features should be sought instead of direct surgical intervention.
\end{abstract}

Keywords: Brown tumor, Normocalcemic hyperparathyroidism, Computed tomography, Multiple sclerosis

*Correspondence: gulinacar@hotmail.com

Department of Oral and Maxillofacial Surgery, Hacettepe University Faculty of Dentistry, Ankara, Turkey

\section{Background}

Primary hyperparathyroidism (PHPT) is a clinical picture that develops due to the increase in uncontrolled parathyroid secretion from the parathyroid glands. As a result 
of inappropriate hypersecretion of parathyroid hormone, excessive calcium reabsorption from the kidneys, phosphaturia, increased vitamin D synthesis, and increased bone resorption occurs [1].

PHPT is more common in patients over the age of 60 but is 2 times more common in women [2]. In primary hyperparathyroidism, hypercalcemia and hypophosphatemia due to the effects of increased parathyroid hormone $(\mathrm{PTH})$ are the main findings of the disease. Clinical manifestations of these basic findings on the skeletal system appear as bone pain, arthralgia, pathological fractures, bone cysts, or "Brown" tumors [3].

As a result of excessive parathyroid hormone release, both osteoblastic and osteoclastic activity in bones increase [4]. Bleeding, vascular fibrous, and granulation tissues, which occur as a result of localized rapid osteoclastic bone turnover with the direct effect of the parathormone, replace normal marrow elements and localized accumulation of giant cells leads to bone expansion. After recurrent bleeding, hemosiderin accumulates in osteolytic cysts, so the lesion appears brown. The term Brown tumor is used because of this appearance. These "tumors" are hypervascular and intensely active in bone scans [5]. Their growth rate is slow, and they cause local damage to the bone. Since this lesion is reactive rather than neoplastic, a Brown tumor cannot be considered as a true tumor case [6-8]. Brown Tumors are benign lesions that mimic malignant bone diseases, seen in approximately $3 \%$ of cases with PHPT and at a rate of $1.5-1.7 \%$ in cases with secondary hyperparathyroidism [2].

Brown Tumors, especially located in the jaw-facial bones, are uncommon findings of PHPT and rarely appear as the first clinical manifestation of the disease [2].

It is important to evaluate clinical, histopathological, and radiological findings together in the differential diagnosis of Brown Tumor. From a radiological point of view, brown tumors appear as well-defined, clear, lytic lesions with thin or broken cortex but without specific symptoms. Computed Tomography (CT) images are in the form of irregular, multilocular osteolytic lesions with "ground glass opacification" containing the cortex that can be interrupted. It has been reported in the literature that CT and magnetic resonance imaging (MRI) findings of brown tumors can be confused with bone marrow malignancies, metastatic carcinoma, and Langerhans cell histiocytosis, although they have tumor-specific appearances [4].

In this case report, the importance of radiological evaluation in the diagnosis and guidance of the destructive lesion observed in the maxilla of a patient with multiple sclerosis is emphasized.

\section{Case presentation}

A 57-year-old female patient applied to Hacettepe University Faculty of Dentistry Department of Oral and Maxillofacial Surgery in August 2020 with complaints of asymmetric swelling and generalized pain in the left maxilla region. In the anamnesis taken, it was learned that the patient had MS and was immobile for about 1 year, and the swelling and pain in the maxilla area had continued for 4 months. In the clinical examination, it was determined that there was no tooth except for the teeth 13-16-18 which were mobile in the maxilla, the maxillary incisors were exfoliated in about 1 year, and the presence of asymmetric swelling in the left maxillary buccal region that can also be observed extra orally (Fig. 1).

In the $\mathrm{CT}$ images taken from the patient, a radiolucent lesion associated with tooth root 13 in the maxilla region, extending from tooth number 13 to tooth number 23 in the alveolar crest region, expanding to the nasal conchae by elevating the base of the nose is detected (Figs. 2, 3, 4).

When radiographic examination and clinical correlation are examined together, blood tests are performed before biopsy in the patient who is approached with the suspicion of Brown Tumor. Laboratory tests were ordered, and serum calcium level was $9.7 \mathrm{mg} / \mathrm{dl}$ (normal $7.6-10.4 \mathrm{mg} / \mathrm{dl}$ ), serum phosphorus was $2.2 \mathrm{mg} /$ $\mathrm{dl}$ (normal $2.5-4.5 \mathrm{mg} / \mathrm{dl}$ ), serum albumine was $3.0 \mathrm{~g} /$ $\mathrm{dL}$ (normal 3.5-5.2 g/dl), and PTH level was $361.4 \mathrm{pg} /$ $\mathrm{ml}$ (normal $12-88 \mathrm{pg} / \mathrm{ml}$ ). When the PTH level is high, a biopsy is performed to confirm the preliminary

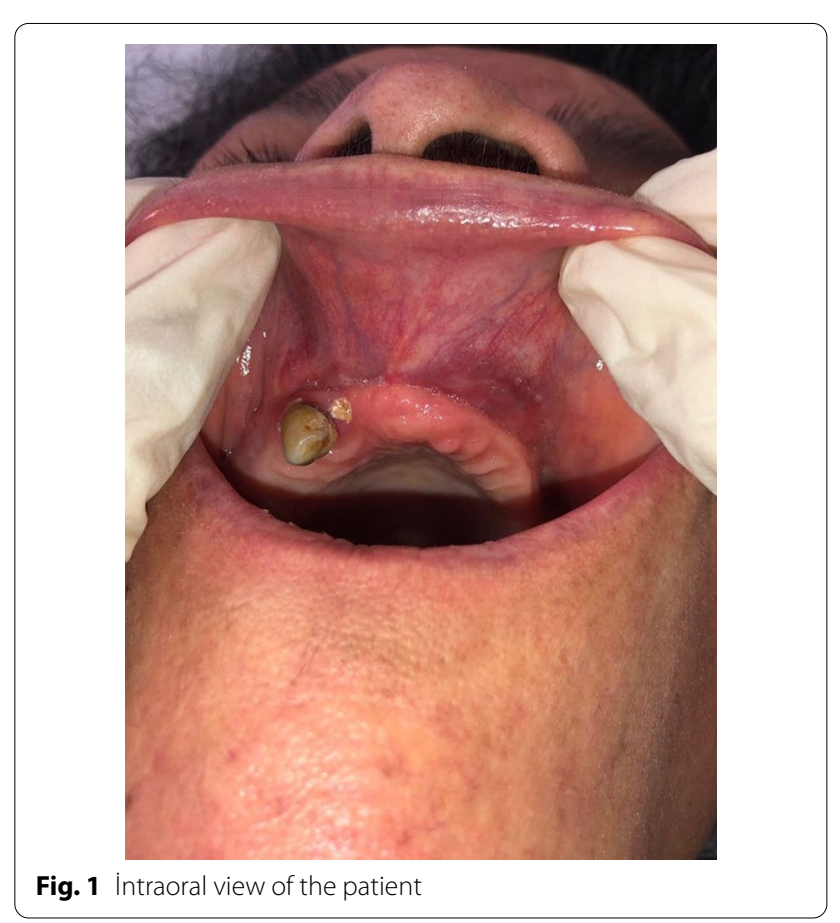




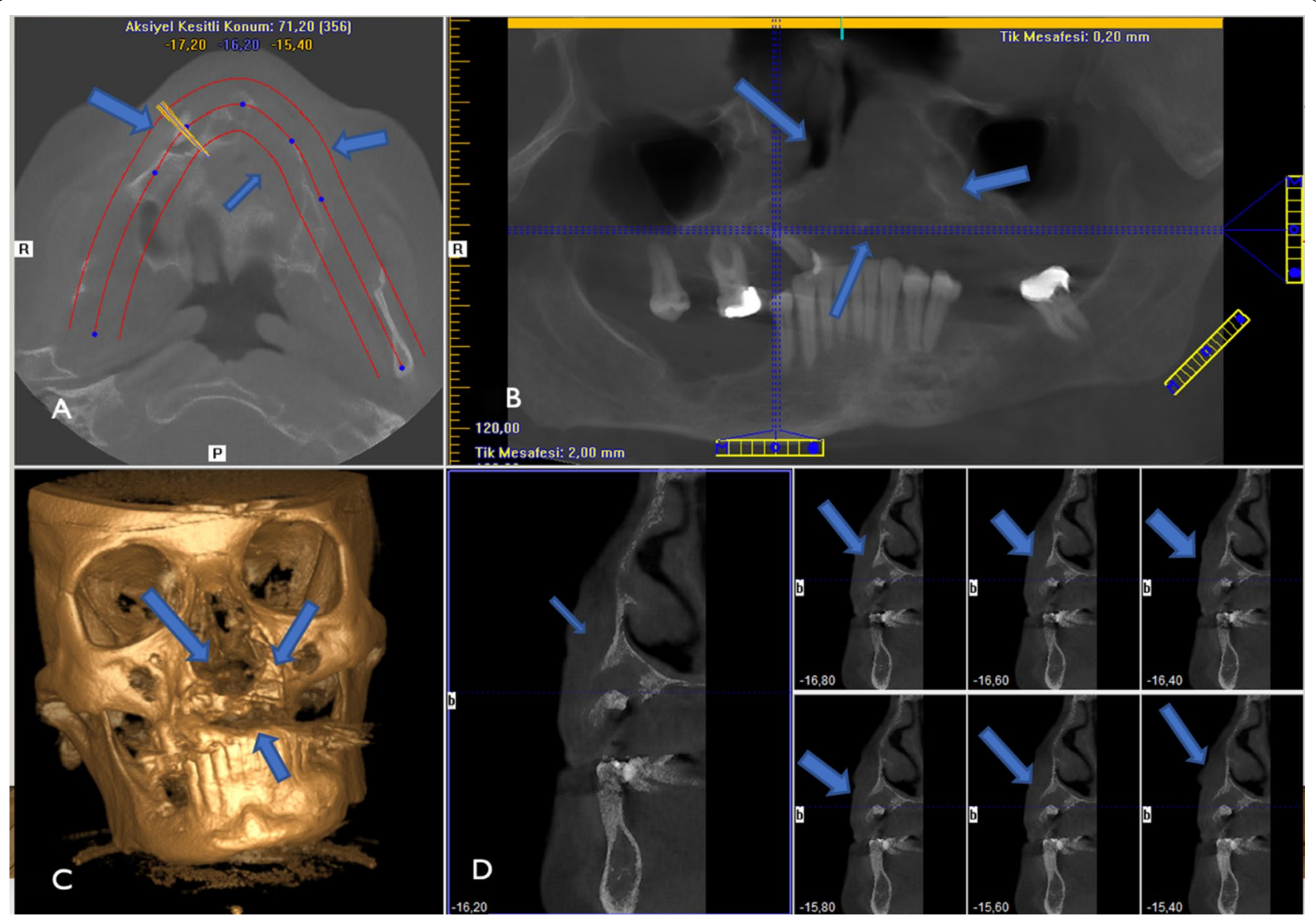

Fig. 2 A CBCT occlusal view, B CBCT frontal view, C CBCT skeletal view, D CBCT side view of the section with the mobile tooth

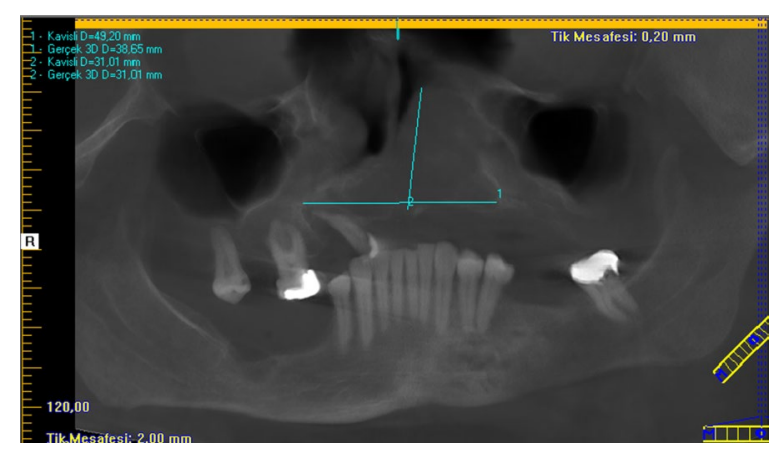

Fig. 3 Lesion size from panoramic radiograph

diagnosis of Brown Tumor (Figs. 5, 6, 7). After confirming the preliminary diagnosis of Brown's tumor, the patient is consulted in the endocrinology department, taking into account the size of the lesion. As a result of the endocrine consultation, an enlargement and presence of nodules in the parathyroid glands was detected.

\section{Discussion}

Hyperparathyroidism is the most common endocrine disease after diabetes and thyroid problems. The incidence can be as high as $1 / 500$ to $1 / 1000$. It is mostly seen in postmenopausal women, between the fourth and sixth decades of life. It can be caused by a solitary adenoma (80-85\%), multiple adenomas (5\%), parathyroid hyperplasia $(10-15 \%)$, and carcinoma $(<1-5 \%)$ of the parathyroid glands [7].

As a result of a continuous increase in $\mathrm{PTH}$, a generalized loss of lamina dura, giant cell granulomas, and demineralization are seen radiologically. As a result of progressive demineralization, decreases in the thickness of buccal cortical plates, mandibular inferior cortex, and trabeculation are observed. Similarly, radiolucencies are observed with a generalized demineralization of the mandibular inferior cortex and sinus wall thickness $[9,10]$.

As a result of secondary osteoporosis development due to increased parathormone levels, bone pain, pathological fractures can be observed. In our case, the 


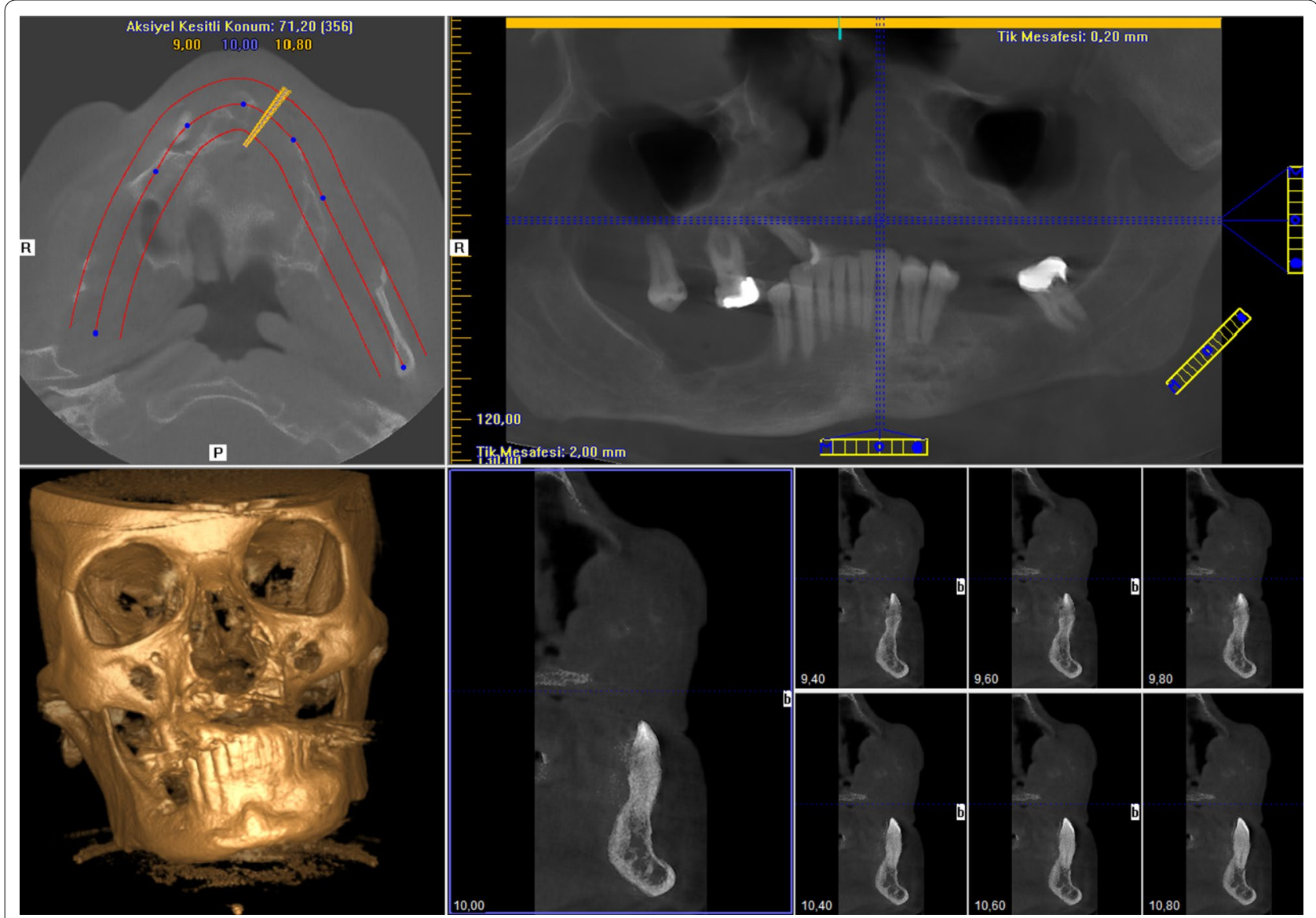

Fig. 4 CBCT view from the area where the lesion is highest; blue arrows

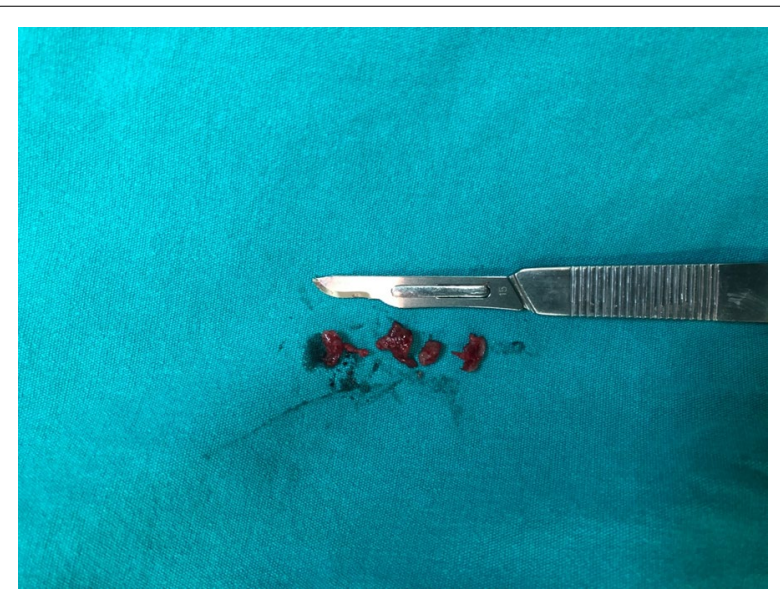

Fig. 5 Biopsy samples

patient applied to our clinic due to generalized and progressive pain at the jawbones [11].

One of the clinical features caused by hyperparathyroidism is Brown Tumors. The incidence of these lesions in primary hyperparathyroidism was approximately $3 \%$, and in secondary hyperparathyroidism, it was $2 \%$. Lamina dura loss and internal/external root resorption can also be observed in advanced stages of the disease [7]. In this case, radiographically $31 \times 49.2 \mathrm{~mm}$ dimensions, irregular limited, extraoral swelling, brown tumor-like radiolucent formation observed in the maxillary region, generalized lamina dura losses, external root resorptions were observed. In the occlusive plan of the CT scans taken, destruction was seen in the buccal cortical bone.

Normocalcemic hyperparathyroidism occurs with PTH elevation, which is not linked to any other reasons. Like in our case, normal calcium levels, low or normal phosphorus levels are monitored. In the literature, 7 brown tumor cases caused by normocalcemic hyperparathyroidism have been reported [12]. Although the prevalence of this disease was reported between 0.4 and $3.1 \%$, it was not fully determined [1]. Many unanswered questions remain about the effect of normocalcemic PHPT on target organs and their epidemiology. In this case, the literature was investigated about whether the patient had 


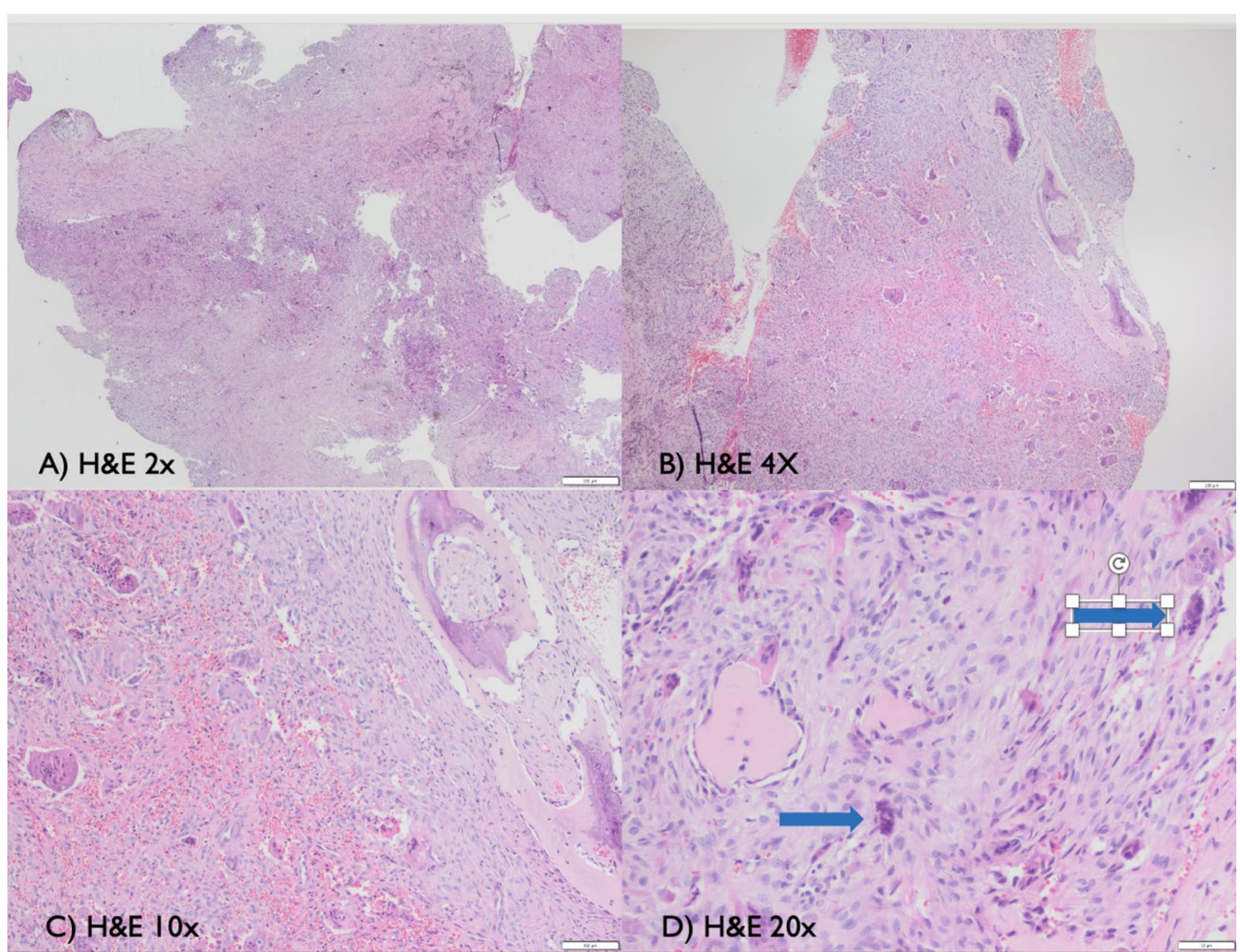

Fig. 6 Histopathological images at different magnifications. A Hematoxylin and eosin with $\times 2$ magnification, $\mathbf{B}$ Hematoxylin and eosin with $\times 4$ magnification, $\mathbf{C}$ Hematoxylin and eosin with $\times 10$ magnification, $\mathbf{D}$ Hematoxylin and eosin with $\times 20$ magnification; lots of multinucleated giant cells blue arrows),

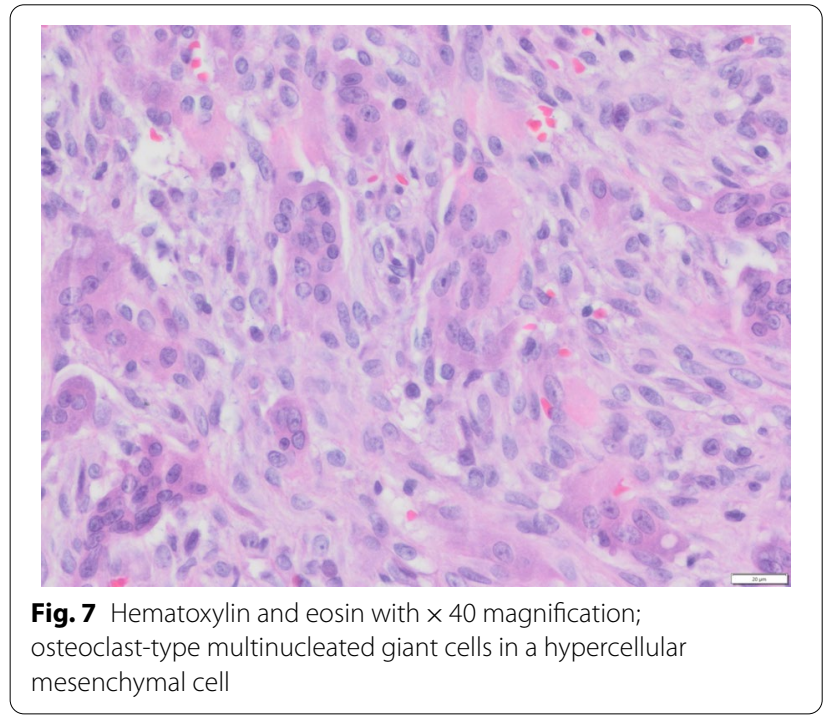

a connection to multiple sclerosis, after the diagnosis of brown tumor, which was followed up with normocalcemic hyperparathyroidism, but no obvious results were found. However, it has been reported that IL-17a, which is increased through T-helper, acts by different mechanisms in both diseases.

MS seen at our patient is a chronic autoimmune central nervous system (CNS) disease characterized by inflammation, demineralization, and axon damage. Of MS patients, $85 \%$ develop ataxia, which can be cerebellar, sensory, or mixed type and may be associated with vertigo. It is rarely seen as a single symptom and usually occurs with muscle weakness and spasticity [12]. In the literature research, it was learned that the bone destruction mechanism of parathormone is caused by the secretion of IL-17a and in the formation of MS, it was learned that the elevated IL-17a level was an effective mediator. However, studies have not found any research on the exacerbation of bone lesions between multiple sclerosis and hyperparathyroidism [13].

The radiological properties of normocalcemic PHPT are similar to primary hyperparathyroidism findings, and osteopenia is common [11].

The first step in the treatment of Brown tumors due to hyperparathyroidism is to adjust the vitamin $\mathrm{D}$ level of HPT or partial tumor resection (PTx). After this 
treatment, the lesion is expected to shrink and PTH levels to normalize. However, in some cases, an increase in tumor sizes can be observed even after PTx. In such cases, an average of 1 or 2 years of follow-up is recommended after resection of the tumor. If symptoms are observed in the patient after 1 or 2 years of follow-up, surgical resection and decompression of brown tumor should be considered. Biopsies after resection reported the giant cells and an increase in osteoblastic activity and bone production. In some large lesions, resection can be considered after the PTH level is normalized and the lesion dimensions are reduced by intralesional steroid injection in the follow-up of the lesion [14].

However, the question mark here is that the increased IL-17a level in Brown Tumor is talking about increasing the osteoporotic state, while the effect of steroids used to increase this situation is unknown. In this case report, the preliminary diagnosis made entirely with radiological findings was confirmed by pathology, and the patient was consulted to the endocrinology department for the necessary treatment. The importance of radiological evaluation is high in such destructive lesions. In the literature, it was stated that only the lesions regressed as a result of the treatment [14]. However, there is a need for studies in which the results of the treatment can be shown radiologically. Thanks to these studies, the difference in bone density with normal bone can be determined and information about recurrence rates can be obtained. In addition, the success rate of the treatment according to the size of the lesion can be supported by radiological studies.

The radiologic similarities of brown tumors and other bone tumors make it difficult to reach a correct diagnosis. A solitary bone lesion of a brown tumor may be difficult to differentiate from an aneurysmal bone cyst, giant cell tumor, solitary bone cyst, and giant cell reparative granuloma [9]. Bone metastases or multiple myeloma may be considered primarily in multifocal osteolytic lesions, especially in cases where serum calcium levels are normal, as in our case. The use of extra radiological examinations at the diagnosis can be beneficial in these cases. One study showed that brown tumors were one of the few lesions that showed osteolytic appearance on radiographs and short T2 on MR imaging, but only 13 cases were found with an MR imaging of the brown tumor in the same study [15]. Only 6 of the 13 cases were published in a radiological journal [9]. In our case, MRI was not performed because access to the MRI device was difficult and expensive. However, there is a need for studies using MR imaging techniques in the diagnosis and treatment stages of the brown tumor seen in the jawbones.

As a result, the importance of the pre-diagnosis placed with radiological findings is stated in this case report and it is seen that it accelerates diagnosis and treatment in terms of PTH. When an irregular deconstructive lesion is detected in the radiological maxilla or mandibula, a detailed anamnesis should be taken. Even if serum calcium levels are normal, it is important to investigate serum parathormone level and evaluate other radiological findings of PTH instead of initially suspecting a malign lesion. In future studies, it is clear that the relationship between the presence and exacerbation of bone lesions in multiple sclerosis and hyperparathyroid patients will facilitate the treatment and follow-up process of these patients. In addition, more studies on radiological findings in the treatment process are needed to facilitate patient follow-up during treatment.

\section{Conclusions}

When a lesion with wide borders is detected, surgical intervention should not be considered first and radiological markers should be investigated thoroughly. It should be noted that relatively common diseases have much rarer subtypes, and it should be considered that the rare symptom of the disease may sometimes be the first diagnostic marker. In addition, more studies are needed in the literature on a possible relationship between brown tumor and multiple sclerosis.

\section{Abbreviations \\ MS: Multiple sclerosis; COPD: Chronic obstructive pulmonary disease; PHPT: Primary hyperparathyroidism; PTH: Parathyroid hormone; CT: Computed tomography; MRI: Magnetic resonance imaging; CNS: Central nervous system; PTx: Partial tumor resection.}

\section{Acknowledgements}

Not applicable.

\section{Authors' contributions}

NE made significant contributions to defining the concept of the study, interpreting the radiological and pathological images and analyzing the findings. SA contributed significantly to the study design, interpretation of radiological and pathological images, and drafting of the study. GA contributed to obtaining the data, drafting and revising the working paper. The authors agree to be personally responsible for their own contributions. All authors read and approved the final manuscript.

\section{Funding}

Not applicable.

\section{Availability of data and materials}

The datasets used and/or analyzed during the current study are available from the corresponding author on reasonable request.

\section{Declarations}

Ethics approval and consent to participate

A clear and understandable informed consent form was obtained from the patient in accordance with her own language. The patient's consent form was sent as an additional file. This article does not contain any studies with human or animal subjects performed by the any of the authors. 


\section{Consent for publication}

An understandable publication consent was obtained from the patient in her own language for the publication of the photographs and tomography images in the article.

\section{Competing interests}

The authors declare no competing interests.

Received: 22 September 2021 Accepted: 5 February 2022

Published online: 15 February 2022

\section{References}

1. Güldiken S, Tunçbilek N, Ökten Ö, Tuğrul A (2004) The radiographic features of brown tumor associated with primary hyperparathyroıdısm. Turkiye Klinikleri J Endocrin 2(3):209-212

2. Bassler T, Wong E, Brynes R (1993) Osteitis fibrosa cystica simulating metastatic tumor. An almost-forgotten relationship. Am J Clin Pathol 100(6):697-700. https://doi.org/10.1093/ajcp/100.6.697

3. Emın AH et al (2004) Normocalcemic hyperparathyroidism presented with mandibular brown tumor: report of a case. Auris Nasus Larynx 31(3):299-304. https://doi.org/10.1016/j.anl.2004.03.014

4. Demir AK, Kutlutürk F, Gül SS, Gümüşay Ö (2018) Brown tumor caused by primary hyperparathyroidism mimicking giant cell tumor of bone. J Contemp Med 8(2):171-173. https://doi.org/10.16899/gopctd.370895

5. Blinder G, Hiller N, Gatt N, Matas M, Shilo S (1997) Brown tumor in the cricoid cartilage: an unusual manifestation of primary hyperparathyroidism. Ann Otol Rhinol Laryngol 106(3):252-253. https://doi.org/10.1177/00034 8949710600314

6. Sn S, Sm G, Sato Y, Ra R (1999) Brown tumor of the palate in a patient with primary hyperparathyroidism. Ann Otol Rhinol Laryngol 108(1):91-94. https://doi.org/10.1177/000348949910800114

7. Kamal AF, Isdianto PA, Abdullah A, Kodrat E (2020) Brown tumors of hyperparathyroidism misdiagnosed as multifocal giant cell tumors of bone: a case report. Hum Pathol Case Rep 21:200385. https://doi.org/10. 1016/j.ehpc.2020.200385

8. Parisien M, Sj S, Shane E, Dw D, Jp B (1990) Bone disease in primary hyperparathyroidism. Endocrinol Metab Clin North Am 19(1):19-34. https://doi. org/10.1016/S0889-8529(18)30337-2

9. Diacinti D, Cipriani C, Biamonte F, Pepe J, Colangelo L, Kripa E, lannacone A, Orlandi M, Guarnieri V, Diacinti D, Minisola S (2020) Imaging technologies in the differential diagnosis and follow-up of brown tumor in primary hyperparathyroidism: case report and review of the literature. Bone Reports 14:100745. https://doi.org/10.1016/j.bonr.2020.100745

10. Kişnişci RŞ, Duran S (1990) Primer Hiperparatiroidizme Bağlı Çenelerde Görülen Dev Hücreli Granüloma (Brown Tümör)(Bir Vaka Nedeniyle). Gazi Üniversitesi Diş Hekimliği Fakültesi Dergisi 7(2):179-188

11. Armutlu K, Karabudak R, Nurlu G (2001) Physiotherapy approaches in the treatment of ataxic multiple sclerosis: a pilot study. Neurorehabil Neural Repair 15(3):203-211. https://doi.org/10.1177/154596830101500308

12. Meydan N et al (2005) Normokalsemi Ile Seyreden Ve Metastatik Kemik Hastalığını Taklit Eden Bir Brown Tümörü Olgusu. ADÜ Tıp Fakültesi Dergisi 6(3):33-36

13. Pacifici R (2016) The role of II-17 and Th17 cells in the bone catabolic activity of Pth. Front Immunol 7:57. https://doi.org/10.3389/fimmu.2016. 00057

14. Queiroz IV, Queiroz SP, Medeiros R, Ribeiro RB, Crusoé-Rebello IM, Leão JC (2016) Brown tumor of secondary hyperparathyroidism: surgical approach and clinical outcome. Oral Maxillofac Surg 20(4):435-439. https://doi.org/10.1007/s10006-016-0575-0

15. Xie C et al (2019) Imaging of brown tumours: a pictorial review. Insights Imaging 10(1):1-9. https://doi.org/10.1186/s13244-019-0757-z

\section{Publisher's Note}

Springer Nature remains neutral with regard to jurisdictional claims in published maps and institutional affiliations.

\section{Submit your manuscript to a SpringerOpen ${ }^{\circ}$ journal and benefit from:}

- Convenient online submission

- Rigorous peer review

- Open access: articles freely available online

- High visibility within the field

- Retaining the copyright to your article

Submit your next manuscript at $\boldsymbol{\Delta}$ springeropen.com 